\title{
BAND PASS FILTER DENGAN METODE HAIRPIN RESONATOR PADA FREKUENSI X-BAND
}

\author{
Arfan Ridwan Hartawan', Trasma Yunita ${ }^{2}$, Levy Olivia Nur ${ }^{3}$ \\ 1, 2, ${ }^{3}$ Fakultas Teknik Elektro, Universitas Telkom \\ 19arfanridwanh@gmail.com, ${ }^{2}$ trasmayunita@telkomuniversity.ac.id, ${ }^{3}$ levyolivia@telkomuniversity.ac.id
}

\begin{abstract}
Abstrak
Filter adalah suatu perangkat dalam susunan elektronika telekomunikasi yang berfungsi untuk menyeleksi sinyal tertentu. Hairpin filter adalah salah satu jenis filter yang sering digunakan pada frekuensi microwave. Filter ini dibentuk dari resonator filter edge-couple dengan membalik ujung resonator ke bentuk " $U$ ", ini tentunya akan mengurangi panjang dan meningkatkan aspek rasio secara berarti dalam susunan mikrostipnya. Dalam metode hairpin terdapat saluran terkopel dan saluran tidak terkopel. Perancangan filter BPF dengan metode hairpin ini bekerja pada frekuensi X-Band (9770 MHz) berbasis mikrostrip untuk radar cuaca. Pada realisasi filter ini mempunyai nilai bandwidth $230 \mathrm{MHz}$ dengan insertion loss dibawah $-3 \mathrm{~dB}$, return loss $-13 \mathrm{~dB}$, dan VSWR = 1,56.
\end{abstract}

Kata Kunci: Hairpin filter, X-Band, mikrostrip

\begin{abstract}
Filter is a device in the telecommunications electronics that serves to select a particular signal. Hairpin filter is one type of filter that used in microwave frequencies. This filter is formed from the edge-couple resonator filter by reversing the tip of the resonator to the " $U$ " shape, this will certainly reduce the length and significantly increase the aspect ratio in the microspheres. In the hairpin method there are uncrossed and uncrossed channels. Design of BPF filter with hairpin method works on X-Band frequency (9770 MHz) based on microstrip for weather radar. In the realization has a bandwidth of $230 \mathrm{MHz}$ with insertion loss less than $-3 \mathrm{~dB}$, return loss $-13 \mathrm{~dB}$, and VSWR $=1,56$.
\end{abstract}

Keywords: Hairpin filter, X-Band, microstrip

\section{Pendahuluan}

Radar adalah sebuah perangkat elektronika yang berfungsi untuk mendeteksi dan memberikan informasi letak suatu objek. Beropasi dengan mengirimkan jenis tertentu dari suatu gelombang kemudian menerima dan mendeteksi sinyal yang diterima [1]. Dalam blok komunikasi radar khususnya penerima (receiver) terdapat sebuah filter yang berfungsi menyeleksi band frekuensi tertentu. Filter mikrostrip adalah salah satu pilihan untuk merancang sebuah filter karena dapat mengubah ukuran filter menjadi lebih kecil, ringan, biaya yang lebih rendah, dan juga mudah dalam perancangannya. Salah satu filter yang dapat digunakan adalah hairpin filter. Filter ini mempunyai struktur yang tersusun rapi, mempunyai konsep yang dihasilkan dari penggabungan lipatan-lipatan resonator pararrel edge couple dan half-wavelength resonator yang dibentuk menjadi "U”.

Pada penlitian sebelumnya [2] telah dirancang sebuah BPF menggunakan ring square resonator pada frekuensi 9,4 GHz yang memiliki bandwidth 63 $\mathrm{MHz}$, menggunakan substrat Roger Duroid 5880. Hasil yang didapat adalah nilai return loss sebesar 10,977 dB dan insertion loss sebesar $-3,917 \mathrm{~dB}$. Pada penelitian yang lain [3] telah dirancang sebuah BPF menggunakan metode hairpin untuk frekunesi $\mathrm{Wi}-\mathrm{Fi}$ menggunakan material substrat FR-4 dengan nilai bandwidth $130 \mathrm{MHz}$, return loss $-26,95 \mathrm{~dB}$, insertion loss $-14,7 \mathrm{~dB}$ serta VSWR 1,39. BPF ini mengalami pergeseran frekuensi tengah sebesar $50 \mathrm{MHz}$ dari perancangan yang disebabkan fabrikasi, rugi-rugi konektor, dan perbedaan parameter dari bahan FR-4 dari simulasi dan realisasi.

Filter hairpin yang dirancang diharapkan dapat mempunyai tingkat slope yang tajam dengan parameter yang lebih baik dari sebelumnya pada frekunesi tinggi (X-Band) dengan bandwidth yang sempit agar dapat digunakan pada radar cuaca.

\section{Tinjauan Makalah}

Radar adalah sebuah sistem elektromagnetik untuk mendeteksi lokasi dari sebuah objek. Beroperasi dengan mengirimkan suatu jenis gelombang dan mendeteksi karakteristik sinyal pantulan. Radar digunakan untuk memperluas kemampuan indera seseorang untuk mengamati lingkungan, terutama indera penglihatan, namun nilai radar tidak terletak pada menjadi pengganti untuk mata, tetapi melakukan apa yang mata tidak 
bisa lakukan [1]. Radar tidak dapat melihat spesifik seperti mata, juga bukan mampu untuk mendeteksi "warna" dari objeknya, namun radar dirancang untuk melihat melalui kondisi yang mata tidak mampu melihat, seperti kegelapan, kabut, hujan dan salju [1]. Selain itu, radar memiliki keuntungan untuk dapat mengukur jarak atau jangkauan ke objek, yang menjadi keuntungan paling penting sebuah radar.

Radar cuaca mempunyai cara kerja yang sama seperti radar yang lainnya, dengan prinsip dasar mengirimkan gelombang elektromagnetik lalu dipantulkan kembali oleh target yang disebut echo. Echo yang diterima akan diolah sedemikian rupa sehingga kita bisa mengetahui karakteristik awan yang sedang kita deteksi.

\subsection{Filter}

Filter adalah suatu jaringan yang memiliki dua catuan yang berfungsi untuk mengontrol respon frekuensi pada wilayah tertentu dalam sistem gelombang mikro dengan mentransmisikan frekuensi pada daerah passband dan atenuasi pada daerah stopband [4]. Filter digunakan untuk mengontrol respon frekuensi dalam passband, dan redaman dalam stopband. Filter sendiri terdapat pada rangkaian pengirim ataupun penerima, yang berguna untuk menyeleksi frekuensi yang dibutuhkan pada sistem tersebut.

Dari filter yang dibuat, akan diacu parameter filter yaitu frekuensi kerja, impedansi input/output, frekuensi cut-off, kecuraman, lebar pita, dan ripple. Filter secara umum dapat dijelaskan pada Gambar 2.

\subsection{Saluran Mikrostrip}

Mikrostrip adalah salah satu saluran transmisi yang terdiri dari konduktor strip tipis dengan lebar W diatas substrat yang memiliki konstanta dielektrik Er tertentu dan sebuah konduktor ground plane dibawahnya [5]. Dengan persamaan Richard's Transformation dan Kuroda's Identities adalah menggunakan variabel Zo (lebar mikrostrip) untuk membuat lumped element digantikan oleh transmission line. Jadi membutuhkan induktansi L untuk filter prototipe yang dinormalisasi dengan frekuensi cut-off $\square \mathrm{c}=1$ dan admitansi go $=1 \mathrm{kita}$ dapat menggantinya dengan $\square / 8$ saluran mikrostrip yang mempunyai Zo = L [6]. Pada saat ukuran mikrostrip di kurangi sehingga dimensinya menjadi lebih kecil dibandingkan dengan panjang gelombang, maka mikrostrip dapat digunakan sebagai elemen lumped Dalam saluran mikrostrip, terdapat ukuran panjang (L) dan lebar resonator (W) yang dapat dicari dengan persamaan 1 sampai 6 .

- Untuk $\mathrm{w} / \mathrm{h}<2$

$$
W=\frac{8 e^{A}}{e^{2 A}-2} \times h
$$

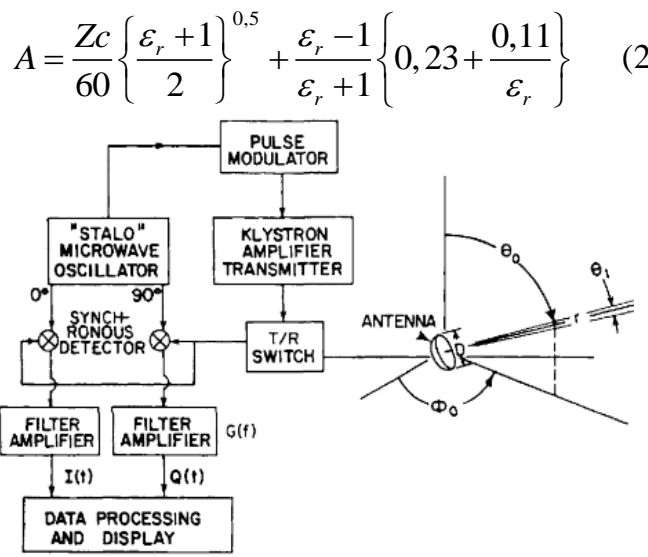

Gambar 1. Blok Diagram Radar Cuaca [5]

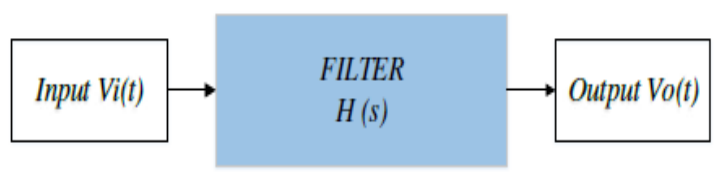

Gambar 2. Diagram Blok Filter

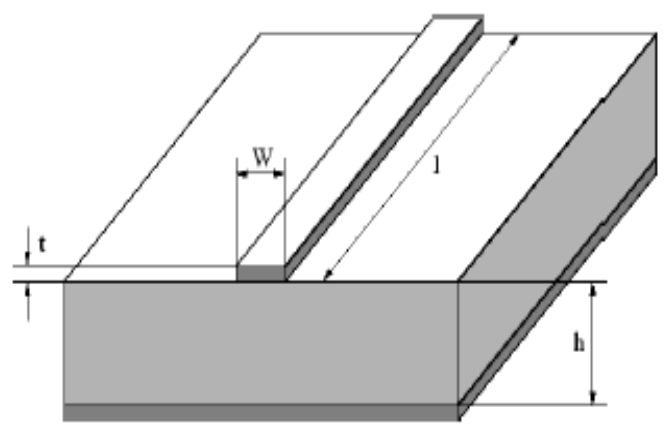

Gambar 3. Bentuk geometri mikrostrip [5]

- Untuk w/h>2

$$
\begin{gathered}
W=\frac{2}{\pi}\left\{\begin{array}{c}
(B-1)-\ln (2 B-1) \\
+\frac{\varepsilon_{r}-1}{2 \varepsilon_{r}}\left[\begin{array}{l}
\ln (B-1) \\
+0,39-\frac{0,61}{\varepsilon_{r}}
\end{array}\right]
\end{array}\right] \times h \\
B=\frac{60 \pi^{2}}{z_{c} \sqrt{\varepsilon_{r}}}
\end{gathered}
$$

Untuk mendapatkan panjang dari satu resonator dapat digunakan persamaan 5 dan 6 .

$$
\begin{gathered}
L=\frac{(\beta l)\left(\frac{\pi}{180}^{\circ}\right)}{\sqrt{\varepsilon_{e}} k_{0}} \\
k_{0}=\frac{2 \pi f}{c}
\end{gathered}
$$

\subsection{Hairpin Resonator}

Hairpin filter adalah filter dengan struktur kompak. Konsep dari filter ini diperoleh dengan

Jurnal Penelitian dan Pengembangan Telekomunikasi, Kendali, Komputer, Elektrik, dan Elektronika 
melipat resonator dari parallel-coupled dan halfwavelength resonator yang digabungkan menjadi bentuk "U" [6]. Bentuk "U" resonator inilah yang disebut Hairpin resonator, oleh sebab itu persamaan desain yang sama untuk parallelel-coupled dan halfwavelength resonator filter dapat digunakan [6]. Namun, dalam melipat resonator, maka perlu memperhitungkan pengurangan panjang coupledlength, yang mengurangi kopling antara resonator [6]. Juga, jika dua lengan masing-masing Hairpin resonator terlalu dekat, mereka berfungsi sebagai sepasang coupled-line sendiri yang dapat memiliki efek pada kopling juga.

Pada penelitian yang dilakukan, fungsi dari resonator yang disusun secara berjajar dengan model huruf $U$ menentukan parameter-parameter yang dibutuhkan oleh sebuah filter seperti bandwidth, return loss, dan insertion loss.

\section{Metoda Perancangan}

\subsection{Spesifikasi Filter dan Substrat}

Sesuai dengan radar X-Band milik BPPT yang bekerja sama dengan JAMSTEC, maka spesifikasi yang dirancang dalam perancangan sebuah BPF pada penelitian ini adalah sebagai berikut :

- Frekuensi kerja : 9,770 GHz

- Bandwidth : $2 \mathrm{MHz}$

- Insertion loss $: \geq-3 d B$

- Return loss : $\leq-15 d B$

- Respon Frekuensi: Chebyshev

Substrat yang digunakan pada perancangan dan fabrikasi adalah Roger Duroid 5880. Spesifikasi dari substrat yang akan dipakai dapat dilihat pada Tabel 1.

\subsection{Perancangan Dimensi Filter}

Setelah dilakukan perhitungan parameterparameter dari filter hairpin, maka dibuatlah filter hairpin dengan bantuan aplikasi CST DESIGN ENVIRONMENT dengan perhitungan yang sudah ada. Dimensi filter yang dirancang dapat dilihat pada Gambar 5.

Filter ini dibuat berdasarkan perhitungan panjang, lebar, dan jarak antar resonator. Panjang L1 dan L2 yaitu masing-masing $3 \mathrm{~mm}$, panjang slide factor $5 \mathrm{~mm}$, dan lebar saluran resonator adalah 4,9. Jarak resonator $\mathrm{S} 1$ adalah $6 \mathrm{~mm}$ dan $\mathrm{S} 2$ adalah 6.1 $\mathrm{mm}$. Hasil simulasi dari filter dapat dilihat pada gambar dibawah ini.

Dari hasil simulasi perancangan awal diatas, terlihat bahwa didapatkan frekuensi tengah filter 9,7337 GHz. Hasil simulasi belum sesuai dengan spesifikasi filter, yaitu frekuensi tengah 9,770 GHz. Untuk menggeser frekuensi tengah, didapatkan dengan cara menambah atau mengurangi panjang saluran resonator dan untuk bandwidth optimasi dapat dilakukan dengan mengubah jarak antar resonator, semakin jauh jarak antar resonator maka semakin kecil koefisien kopling dan semakin kecil bandwidth-nya.

\subsection{Tuning Perancangan Filter}

Pada proses simulasi, hasil yang didapat masih kurang sesuai dengan spesifikasi yang diharapkan, yaitu bergesernya frekuensi tengah sebesar $0,04 \mathrm{GHz}$ maka dilakukan proses tuning yang akan menunjukkan seberapa besar perubahan karakteristik filter pada tiap-tiap parameter yang dioptimasi sehingga didapatkan spesifikasi filter yang diinginkan.

Proses tuning dimulai dari merubah panjang total dari masing-masing resonator. Perubahan yang didapatkan oleh perubahan panjang ditampilkan pada

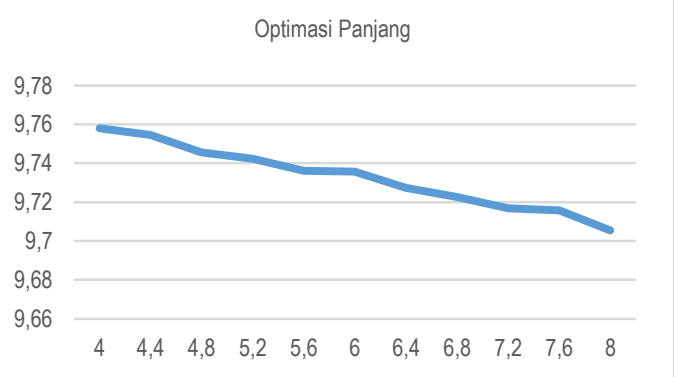

Gambar 7.

Tabel 1. Spesifikasi substrat yang digunakan

\begin{tabular}{|c|c|}
\hline Jenis Substrat & Roger Duroid RT5880 \\
\hline Konstanta Dielektrik & 2,2 \\
\hline Dielectric Loss Tangen & 0,0009 \\
\hline Tebal Substrat & $1,575 \mathrm{~mm}$ \\
\hline Tebal Konduktor & $0,035 \mathrm{~mm}$ \\
\hline
\end{tabular}

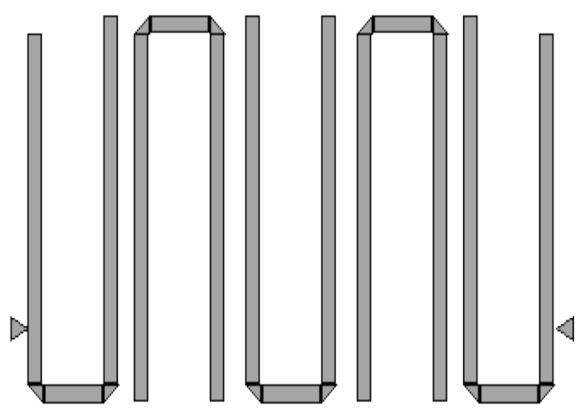

Gambar 4. Hairpin Resonator

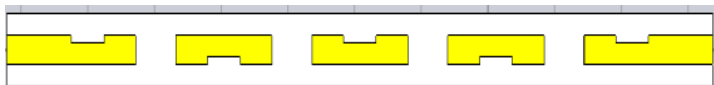

Gambar 5. Dimensi Simulasi

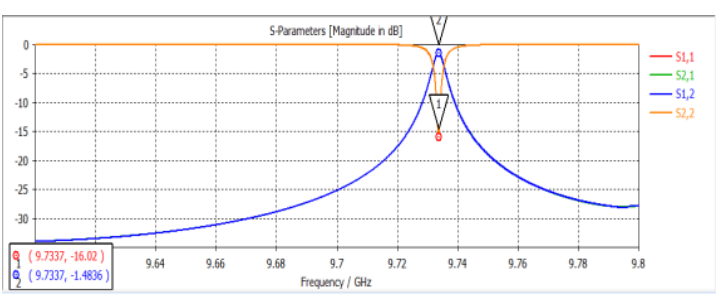

Gambar 6. Hasil Simulasi Awal 


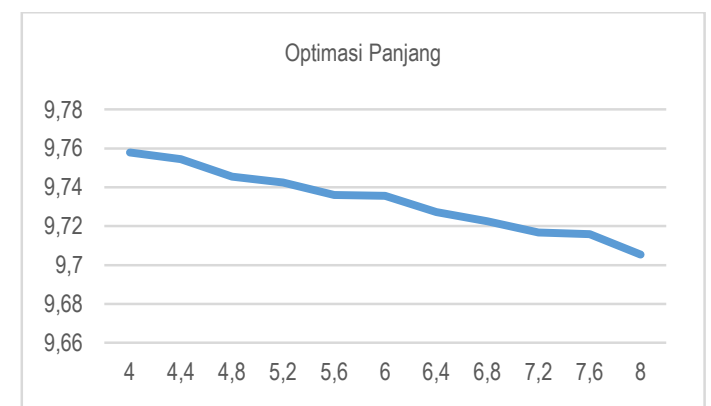

Gambar 7. Optimasi Panjang

Dari Gambar 7 dapat ditarik kesimpulan bahwa semakin panjang panjang sisi kanan dan kiri resonator, maka semakin rendah frekuensi kerjanya. Karena pada spesifikasi dibutuhkan frekuensi tengah sebesar 9,770 maka diambil panjang sisi kiri dan kanan adalah $1 \mathrm{~mm}$ untuk masing-masing.

Proses tuning dilanjutkan dengan optimasi pada parameter lebar saluran resonator dan saluran pencatu, yang dapat dilihat pada Gambar 8 .

Sesuai dengan hasil pada Gambar 8, maka dapat ditarik kesimpulan bahwa semakin lebar resonator, maka semakin rendah frekuensi kerja dari filter tersebut.

Optimasi yang terakhir dilakukan pada slide factor. Sesuai dasar teori yang sudah dijelaskan bahwa slide factor akan mempengaruhi terhadap frekuensi kerja filter dan agar tidak terjadi self coupling harus 1-3 kali lebar resonator. Gambar 9 menunjukkan optimasi dari slide factor.

\subsection{Optimasi Akhir Perancangan}

Sesuai dengan optimasi yang telah dilakukan, untuk mendapatkan hasil yang diinginkan maka perubahan dimensi yang dilakukan pada masingmasing resonator dan jarak antar resonator disajikan pada Tabel 2.

Hasil parameter yang didapatkan dari perancangan akhir filter hairpin tersebut disajikan pada Gambar 10.

Nilai dari return loss sebesar $-21 \mathrm{~dB}$ lebih kecil dari -15 dB atau secara numerik daya yang kembali lagi ke catuan sangat kecil sekitar 0,01 sehingga terjadi transfer daya maksimum. Sedangkan keluaran yang dihasilkan oleh metode hairpin resonator dengan substrat Roger Duroid RT5880 adalah -0,732 atau secara numerik daya yang diteruskan sekitar 0,8 dari daya yang dikirimkan. Adapun frekuensi kerja yang diharapkan adalah 9,69-9,71 GHz sehingga adanya atenuasi di frekunesi lainnya tidak mengganggu frekuensi kerja dari filter yang dirancang.

\section{Hasil Pengukuran dan Analisis}

Setelah dilakukan perancangan dengan menggunakan simulasi di perangkat lunak maka dilakukan fabrikasi sesuai dengan simulasi, yang ditunjukkan pada Gambar 11.
Hasil pengukuran S11 dari BPF ditunjukkan pada Gambar 12 yaitu filter memiliki hasil yang berbeda dengan simulasi, frekuensi tengah tidak bergeser akan tetapi nilai magnitude nya berbeda dengan simulasi, hasil yang didapat adalah $-13 \mathrm{~dB}$.

VSWR adalah nilai perbandingan antara amplitude tegangan maksimum terhadap tegangan minimum, VSWR yang ideal adalah bernilai 1 . Karakteristik VSWR juga identik dengan karakteristik yang dihasilkan oleh return loss. Gambar 13 menunjukkan karakteristik VSWR dari hasil realisasi.

Tabel 2. Optimasi Akhir Perancangan

\begin{tabular}{|l|c|c|}
\hline Dimensi & Perhitungan $(\mathrm{mm})$ & Optimasi $(\mathrm{mm})$ \\
\hline Tebal Konduktor & 0.035 & 0.035 \\
\hline Tebal Dielektrik & 1.575 & 1.575 \\
\hline Panjang Sisi & 6 & 4 \\
\hline Lebar Resonator & 4.9 & 4.74 \\
\hline Slide Factor & 4.9 & 4.91 \\
\hline $\begin{array}{l}\text { Jarak antar } \\
\text { resonator 1 (S1) }\end{array}$ & 6 & 6.01 \\
\hline $\begin{array}{l}\text { Jarak antar } \\
\text { resonator 2 (S2) }\end{array}$ & 6.1 & 6.1 \\
\hline
\end{tabular}

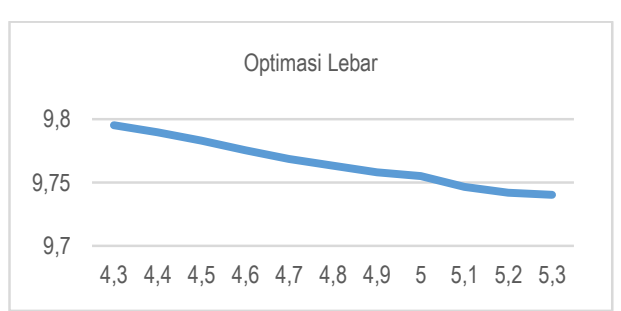

Gambar 8. Optimasi Lebar

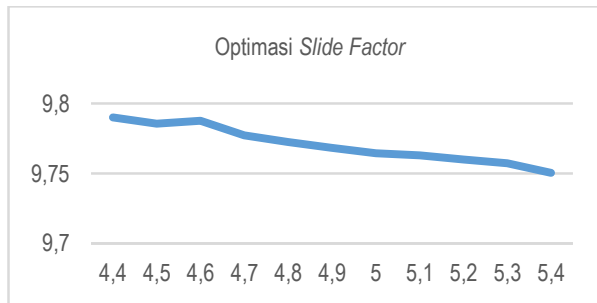

Gambar 9. Optimasi Slide Factor

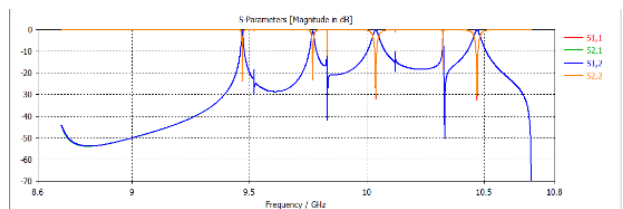

Gambar 10. Hasil S-Parameter simulasi akhir

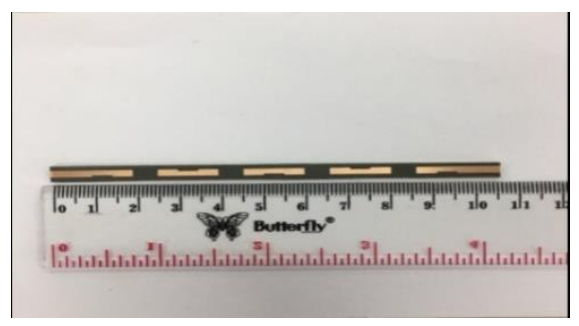

Gambar 11. Realisasi Filter

Jurnal Penelitian dan Pengembangan Telekomunikasi, Kendali, Komputer, Elektrik, dan Elektronika (TEKTRIKA)

Juli 2017 - Volume 2, Nomor 2 


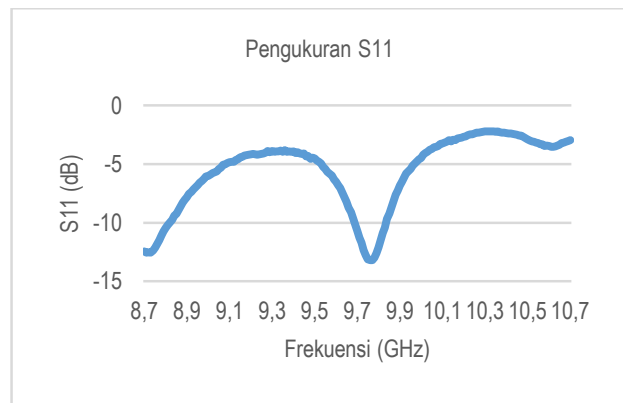

Gambar 12. Return loss Realisasi

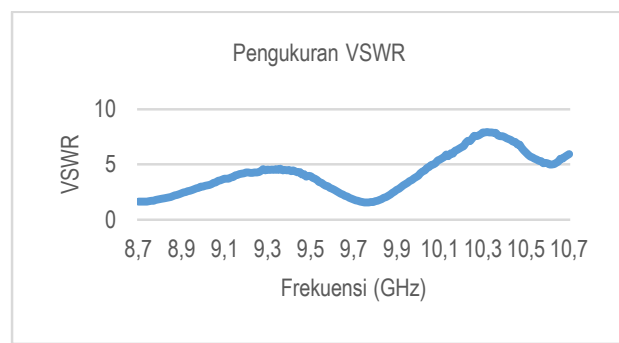

Gambar 13. VSWR Realisasi

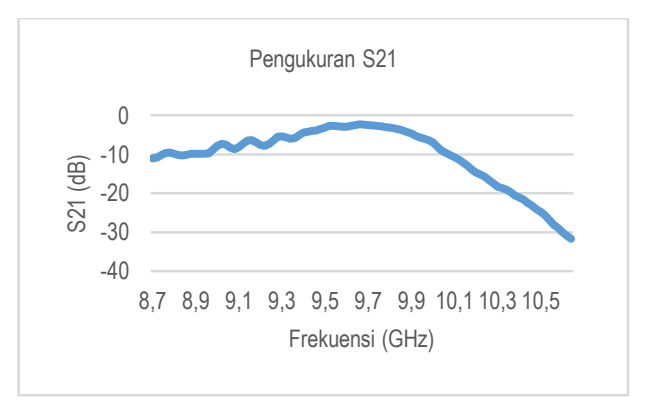

Gambar 14. Insertion loss Realisasi

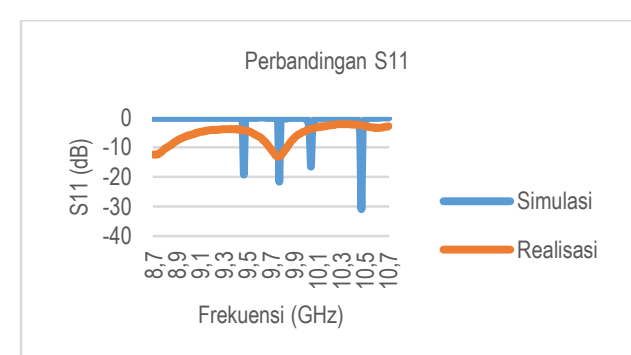

Gambar 15. Perbandingan S11 Simulasi dan Realisasi

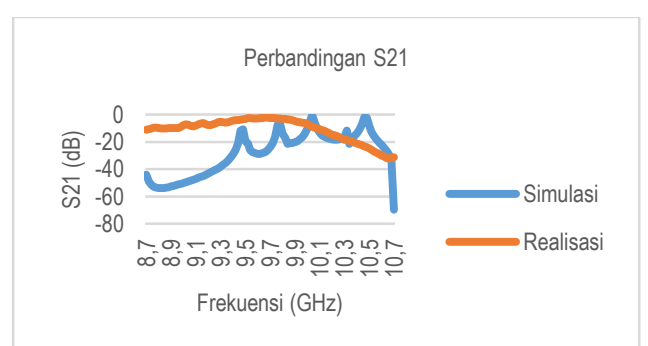

\section{Gambar 16. Perbandingan Hasil S21 Simulasi dan Realisasi}

Hasil yang ditunjukkan pada pengukuran realisasi filter menunjukkan nilai yang baik pada insertion loss-nya, akan tetapi karakteristik yang dihasilkan kurang baik untuk sebuah filter yang mengakibatkan adanya pelebaran bandwidth yang signifikan. Dengan nilai insertion loss $-2,871 \mathrm{~dB}$ namun bandwdith sangat lebar menjadi $230 \mathrm{MHz}$. Gambar 14 menunjukkan karakteristik insertion loss.

Perbandingan antara simulasi dan pengukuran menunjukkan adanya perbedaan yang signifikan. Hal ini dapat disebabkan karena pada proses optimasi / simulasi menggunakan simulator filter dalam keadaan ideal, namun pada realisasi terjadi kesalahan fabrikasi yang telah dilakukan, rugi-rugi konektor, dan interferensi dari frekuensi udara bebas yang sangat berarti untuk komponen elektronika frekuensi tinggi. Gambar 15 menunjukkan perbandingan return loss antara simulasi dan fabrikasi.

Hasil pengukuran seperti diatas memang sering terjadi, bisa diakibatkan oleh kesalahan fabrikasi, losses kabel koaksial pada network analyzer, kesalahan penyolderan, rugi-rugi konektor, dan juga perbedaan parameter substrat yang digunakan, karena mempunyai permitivitas relatif yang bernilai 1,7-2,2. Perbandingan insertion loss ditunjukkan pada Error! Reference source not found.

Berdasarkan hasil pengukuran, terlihat masih banyak ketidaksesuaian yang terjadi antara hasil simulasi dan realisasi. Untuk nilai-nilai parameter seperti return loss, insertion loss, dan VSWR pada dasarnya sudah memenuhi spesifikasi yang ada dan sudah dikatakan cukup baik, akan tetapi pelebaran bandwidth sangat jauh yang diakibatkan karena kondisi perancangan dan lapangan yang tidak ideal, serta hasil print strip-line yang kurang rapi.

\section{Kesimpulan dan Saran}

Berdasarkan hasil simulasi dan perancangan yang sudah dilakukan dapat diambil kesimpulan sebagai berikut:

1. Nilai return loss simulasi berniali $-21 \mathrm{~dB}$ sedangkan pada realisasi bernilai $-13 \mathrm{~dB}$ yang mempunyai frekuensi tengah yang sama yaitu 9,770 .

2. Nilai insertion loss simulasi bernilai $-0,7 \mathrm{~dB}$ sedangkan pada realisasi bernilai $-2,8 \mathrm{~dB}$ adanya perbedaan yang cukup berarti namun hasil masih dapat diteirma.

3. Bandwidth yang diharapkan yaitu $2 \mathrm{MHz}$ tidak didapatkan karena pada realisasi pengukuran mendapatkan bandwidth sebesar $230 \mathrm{MHz}$.

4. VSWR yang didapatkan pada proses simulasi dan realisasi menunjukkan nilai kurang dari 2 .

5. Hasil pengukuran realisasi BPF hairpin menunjukkan nilai yang sudah baik, namun karakteristik yang didapat terutama bandwidth masih jauh dibawah spesifikasi karena dipengaruhi faktor-faktor eksternal pada saat pengukuran.

Dari beberapa kesimpulan yang didapat, dapat disimpulkan bahwa BPF yang telah dirancang belum bisa diaplikasikan pada radar cuaca, karena akan 
menimbulkan interferensi dengan sinyal lain yang ada di atmosfer dengan bandwidth yang sangat lebar tersebut, perlu adanya penelitian selanjutnya.

\section{Daftar Pustaka:}

[1] M. L. Skolnik, INTRODUCTION TO RADAR SYSTEM SECOND EDITION, Singapore: McGraw-Hill Book Co., 1981.

[2] R. M. Putra, B. Setia dan Y. Wahyu, "PERANCANGAN DAN REALISASI BANDPASS FILTER MIKROSTRIP RING SQUARE RESONATOR PADA FREKUENSI X-BAND (9.4 GHZ) UNTUK RADAR FM-CW PENGAWAS PANTAI," Telkom University.

[3] F. C. Sitompul, RANCANG BANGUN BAND PASS FILTER DENGAN METODE HAIRPIN MENGGUNAKAN SALURAN MIKROSTRIP UNTUK FREKUENSI 2,4-2,5 GHz, Medan, 2014.

[4] D. M. Pozar, MICROWAVE ENGINEERING, US: John Wiley \& Sons, Inc., 2012.
[5] F. C. Sitompul dan A. H. Rambe, "RANCANG BANGUN BAND PASS FILTER DENGAN METODE HAIRPIN MENGGUNAKAN SALURAN MIKROSTRIP UNTUK FREKUENSI 2,4-2,5 GHZ," p. 179.

[6] J.-S. Hong dan M. J. Lancaster, Microstrip Filters for RF/Microwave Application, John WIley \& Sons, Inc., 2001.

[7] P. Jarry dan J. Beneat, ADVANCED DESIGN TECHNIQUES AND REALIZATIONS OF MICROWAVE AND RF FILTERS, Hoboken: John WIley \& Sons, Inc, 2008.

[8] G. Matthaei, J. Young dan S. Jones, MICROWAVE FILTERS, IMPEDANCE MATCHING NETWORKS, AND COUPLING STRUCRES, McGraw Hill, 1980.

[9] M. I. Skolnik, Introduction to RADAR SYSTEM, New York: McGRAW-HILL BOOK COMPANY, INC., 1962. 